\title{
Allelopathic Potential of Jasminum Officinale on Weed Species
}

\author{
Steliana RODINO ${ }^{1}$, Marian BUTU ${ }^{*}$, Alina BUTU ${ }^{1}$ \\ ${ }^{1}$ National Institute of Research and Development for Biological Sciences, Splaiul Independentei, no \\ 296, P.O. Box no 17-16, 060031, Bucharest, Romania, Tel. / Fax. +40212200880 \\ * corresponding author: marian.butu@yahoo.com
}

Bulletin UASVM Animal Science and Biotechnologies 74(1)/ 2017

Print ISSN 1843-5262; Electronic ISSN 1843-536X

DOI:10.15835/buasvmcn-asb: 12611

\begin{abstract}
Allelopathy is generally defined as any direct or indirect harmful or beneficial effect of one plant on another mediated by the production allelochemicals. The scope of this study was the evaluation of the potential allelopathic effect of Jasminum officinale against some weed species. The effects of extracts obtained from root, stem and leaves of J. officinale, were evaluated against ragweed (Ambrosia artemisiifolia), ryegrass (Lolium perenne), and Johnsonn grass (Sorghum halepense). The aqueous leachates of jasmine demonstrated promising allelopathic potential by inhibiting seed germination and radicle elongation of all tested species. The best results were observed against Johnsonn grass, with the leaves extract strongly inhibiting the germination rate, while the roots extract inhibited the radicle elongation. The more profound research in the field of allelopathy will eventually lead to the development of bioproducts designed for pest or weed control using allelochemicals.
\end{abstract}

Keywords: allelopathy, plant-plant interaction, inhibiting effect

\section{INTRODUCTION}

Allelopathy is defined as harmful or beneficial effect of one plant on another mediated by the production of chemical compounds, called allelochemicals, which are released into the environment [Lehoczky et al., 2011; Latif et al., 2017]. Release of these allelochemicals, was already demonstrated as a major factor in regulating the plant communities structure in both natural and agroecosystem. Over the time, research on allelopathy principles demonstrated its potential for weeds biological control [Cheng and Cheng, 2015' Worthington and RebergHorton, 2013].

This paper reports studies performed for the evaluation of potential alleopathic effects of $J$. officinale on common weed species.

\section{MATERIALS AND METHODS}

The effects of different plant parts of J. officinale, namely root, stem and leaf, were assessed against the seed germination, emergence and radicle elongation, and coleoptile length of common weed species growing on agricultural lands: ragweed (Ambrosia artemisiifolia), ryegrass (Lolium perenne), and Johnsonn grass (Sorghum halepense).

The aqueous extracts were prepared with distilled water, by maceration for 24 hours at room temperature. The weeds seeds were placed in $90 \mathrm{~mm}$ Petri dishes lined with filter paper. The filter paper was moistened with jasminum extract or distilled water as control. To avoid evaporation, the Petri dishes were covered with parafilm before pressing the top cover. The dishes were maintained at $23^{\circ} \mathrm{C}$ with fluorescent light for 24 hours.

\section{RESULTS AND DISCUSSIONS}

The aqueous extracts of different plant parts of jasmine demonstrated promising allelopathic potential by inhibiting seed germination and radicle elongation of all tested species (Figure 


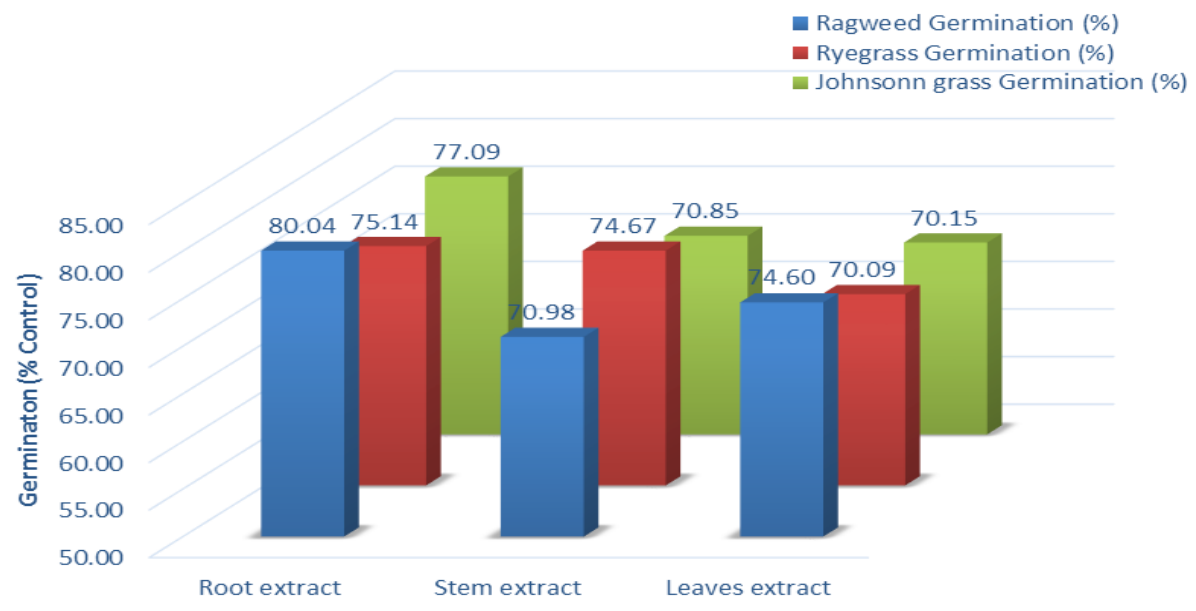

Figure 1. Effect of Jasminum extracts on weeds germination

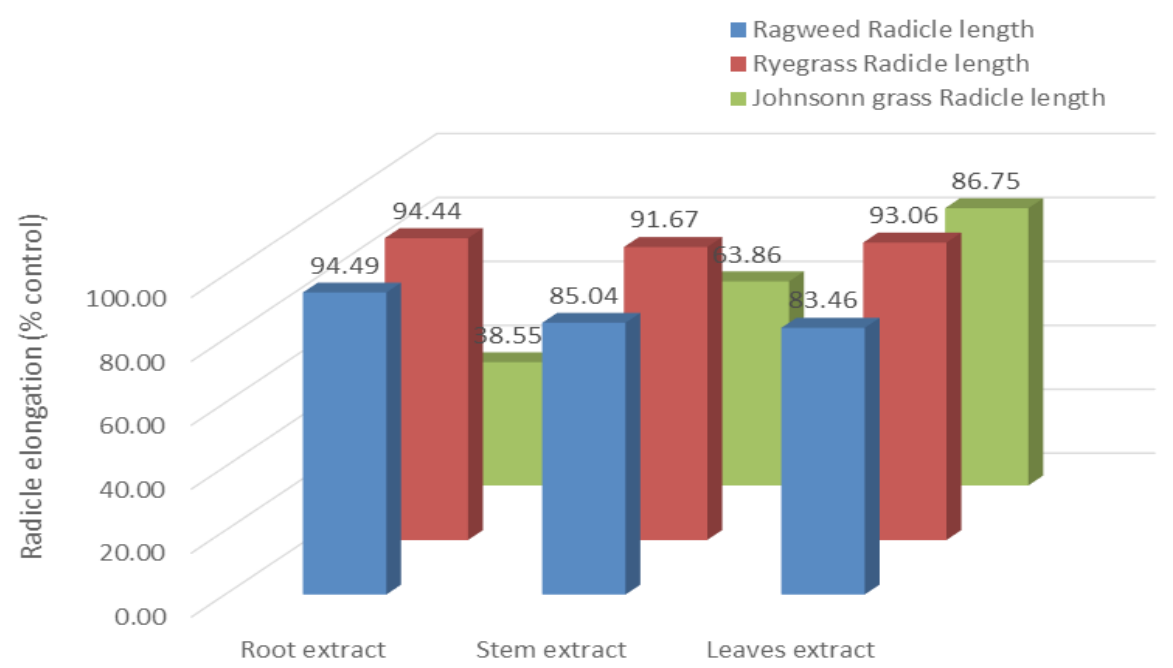

Figure 2. Effect of Jasminum extracts on weeds radicle elongation

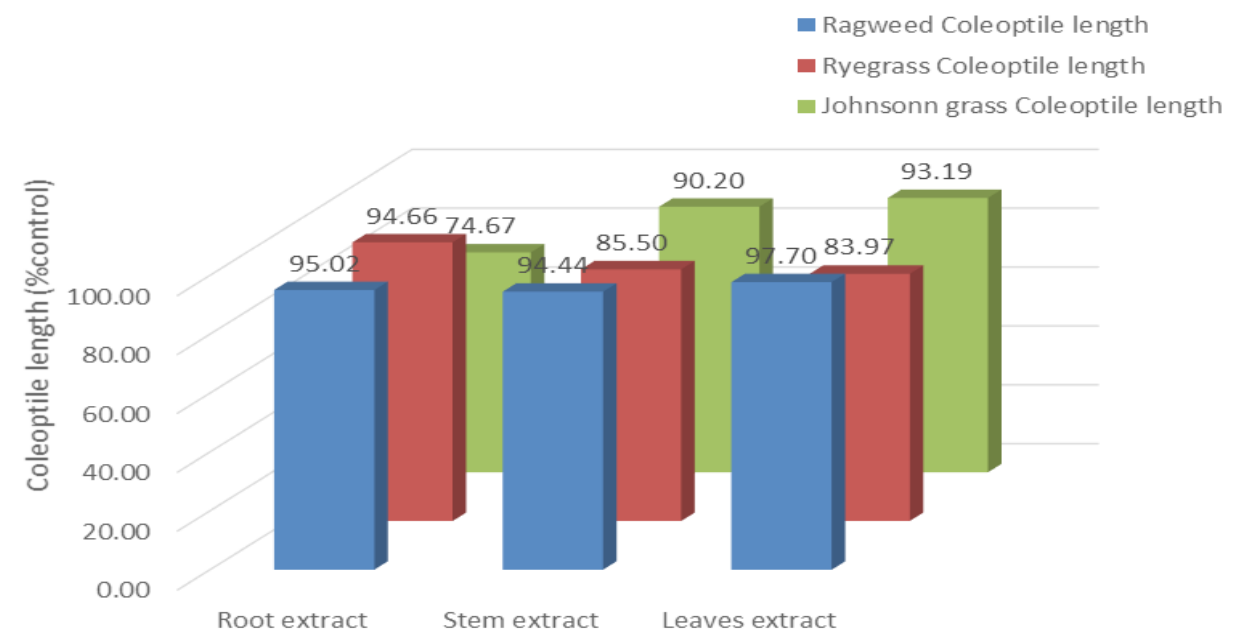

Figure 3. Effect of Jasminum extracts on weeds coleoptile length 
1-3). However, the weed species showed different responses to the treatment with exudates of $J$. officinale. The highest inhibition was observed against Johnsonn grass, with the leaves extract strongly influencing the germination rate, while the roots extract inhibited the radicle elongation.

\section{CONCLUSIONS}

The essential role that allelochemicals play in complex interactions in the environment is being currently elucidated in the scientific progress of humanity. The more profound research in this field will eventually lead to the development of bioproducts designed for pest or weed control using allelochemicals.

Acknowledgements: This work was supported by a grant of the Romanian National Authority for Scientific Research and Innovation, CNCS/
CCCDI -UEFISCDI, project number PN-III-P2-2.1PED-2016-1544, contract number 14PED/2017, within PNCDI III.

\section{REFERENCES}

1. Lehoczky E, Nelima MO, Szabó R, Szalai A, Nagy P (2011). Allelopathic effect of Bromus spp. and Lolium spp. shoot extracts on some crops. Commun Agric Appl Biol Sci. 76(3):537-544.

2. Latif S, Chiapusio G, Weston LA (2017). Chapter Two - Allelopathy and the Role of Allelochemicals in Plant Defence. In: Guillaume B, editor. Advances in Botanical Research. Volume 82: Academic Press; 19-54.

3. Cheng F, Cheng Z (2015). Research Progress on the use of Plant Allelopathy in Agriculture and the Physiological and Ecological Mechanisms of Allelopathy. Frontiers in Plant Science. 6:1020.

4. Worthington M, Reberg-Horton C (2013). Breeding cereal crops for enhanced weed suppression: optimizing allelopathy and competitive ability. J. Chem. Ecol., 39: 213-231. 